\title{
The Discovery of the Parabolic Shape of the Projectile Trajectory*
}

In the fourth volume of his History of the Experimental Method in Italy (Caverni 1891-1900, 4:506-33), Raffaello Caverni fulfilled the promise he had made four years earlier in an introductory overview of his work (ibid., 1:135-36): to prove on the basis of the history of the discovery of the parabolic shape of the projectile trajectory that Galileo claimed the intellectual property of his eminent contemporaries as his own, and to show how this was accomplished. One had the right to expect that the proponent of such an entirely new opinion in a case which he himself considered to be, in the words of Bacon, an instantia praerogativa for the justification of his view, would weigh the value of each individual argument with absolute impartiality and do complete justice to the ambiguity of the given facts. He would have to state his case in compelling logic so that a clear-thinking individual would have no choice, in this case at least, but to believe in the dishonorable theft by a great man. In these expectations we have been disappointed thoroughly by Caverni: his argumentation is in all aspects that of a shrewd lawyer who considers it his task to allow only one side of the question to come to light, to collect everything that might be utilized in favor of his biased reading, to hold back anything which might give rise to the idea that things could be viewed in another way. He believed it permissible for his own purposes to operate with presumptions as if they were facts, and to regard as proven what is at best probable.

Caverni nevertheless serves the cause he champions with comprehensive factual knowledge and an astounding knowledge of the literature. He is especially wellread in the works of Galileo, his correspondence and the handwritten treasures of the Biblioteca Nazionale in Florence. This rare familiarity with the sources of the history of science, with which the friends of Italian science are acquainted from earlier writings by the same author, received extraordinary recognition through an award from the Royal Institute of Venice for Caverni's History of Experimental Method in Italy, whose publication was prefaced with a report by the representative of the Academy, Antonio Favaro [Favaro et al. 1889-90]. However, in these introductory remarks Favaro expresses the hope that the author submit his research to repeated scrutiny and correct his antagonistic judgment of Galileo,

* This article was originally published as Wohlwill 1899. The notes in square brackets are by Giuseppe Castagnetti. The references have been modernized. The list of references can be found in a bibliographical section at the end of the appendix. 
especially his undoubtedly incorrect opinion about the discovery of the parabolic shape of the projectile trajectory. Thus the Academy of Venice and its representatives took precautions in advance so that their recognition would not be interpreted as approval of the attack on the honor and reputation of Galileo, which plays such a great role in Caverni's book. However, this report from such an important source certified the predominant merit of the work by judgment of the Academy of Venice. At the same time it makes it impossible to ignore a contention so emphatically expressed in this work and for which so much evidence is offered. It is not enough to confront the author by fundamentally rejecting his methods of historical research and historiography. In order to refute his case, one must follow the details of his rendering and his treatment of historical sources which were never before available in their entirety. This is what is attempted in the following.

\section{I.}

The fact that Galileo's claim to the discovery of the parabolic shape of the projectile trajectory is contestable has to do with the peculiar way in which his theory of motion was published. It is known that the "new science of local motion" became generally accessible only in his masterpiece [Galilei 1638], which appeared four years before Galileo's death although an outline and the main principles of the theory had been completed four decades earlier. In the work of 1638 , it is apparent that the theory had been completed long before: its axioms were put forth as components of a separate book in the larger work. An older three-part Latin manuscript in strict scientific form offers the actual substance for the successive discussion in Italian, presented in the form of a dialog. As Galileo generally wrote only in the vernacular after his departure from Padua, one has to consider the mere use of Latin in these sections of the Discorsi e dimostrazioni tantamount to a priority claim over any work of similar content written after 1610. Obviously, Galileo's late claim is not definitely binding for the historian even if it is expressed in this form. When Simon Marius says, four years after the discovery of the satellites of Jupiter, that he observed them at least as early as Galileo did, and when Baliani publishes in 1638 that he "discovered" in 1611 that the oscillation periods of two pendula are proportional to the square roots of their lengths, these pretensions expressed by the people concerned cannot be regarded as historical proof for the facts asserted. Similarly, the fact that a pioneering theory of Galileo's is discussed in the Latin text of one of the three books De motu locali is not sufficient proof that it was developed in the period before 1610. It is not only possible, but indeed highly probable, that the older text was not adopted into the context of the greater work unchanged, but rather underwent numerous additions and alterations on the basis of later insights.

Proven, however, is that Galileo had already been working for some time on a three-part manuscript on the theory of motion when he moved to Florence in 
September 1610, and that large sections of this work had been completed. He mentioned this in his report to the State Secretary Vinta of 7 May 1610 as one of three he was hoping to complete if an appropriate position at the Florentine court were to grant him the necessary leisure [Galilei 1890-1909, 10:348-53]. Galileo spoke here of the three books of De motu locali in words very similar to the introduction to the Latin treatises of the Discorsi of 1638, which shared the same title. He said,

It is an entirely new science, since none of the ancients nor any of the new scientists has discovered any of the countless wonderful peculiarities that $I$ am proving for natural and violent motions. Therefore I have every right to call it a new science, and one that I developed from its very beginnings. [Ibid., 10:351-52]

The "new science of local motion," at least the substance of which existed in $\mathbf{1 6 1 0}$ according to this claim, evidently also corresponds to the Latin sections of the later work. Its third book, like the "Fourth Day" of the Discorsi, concerns "violent" motions, i.e., the theory of proietti (projected bodies). Even an entire year earlier (on 23 May 1609) the mathematician Luca Valerio responded by letter [ibid., $10: 244-45]$ to a communication from Galileo concerning his work on naturally moving and projected bodies. Thus, in addition to the research on uniformly accelerating motion, a more or less coherent theory of projectile motion in Galileo's hand must have existed as early as spring 1609.

In a letter addressed to a prince of the Medici House dated 11 February 1609 [ibid., 10:228-30], Galileo spoke of questions which "remained" in regard to the motion of projected bodies. This means that these questions were linked to a series of experiments already completed on the same subject. The additional comments in this letter are of particular interest; until recently they offered the only reference point in the attempt to reconstruct the development of the 1609 theory of projectile motion, without reference to the Latin texts of the Discorsi. These remarks are especially important for answering the question of whether Galileo was aware of the parabolic shape of the trajectory at that time.

Galileo reported to the prince of the grand ducal house that he recently found that cannonballs fired horizontally from an elevated place always deviate from the horizontal and approach the earth at the same speed, independent of the amount of powder used, even if it is just enough to cause them to leave the barrel. He deduced further that for all shots directed horizontally, the ball will reach the earth in the same amount of time, independent of the distance of their points of impact. This time is then identical to the time needed for a ball to fall vertically to the earth from the mouth of the cannon. He recognized a similar effect for shots directed diagonally upward: shots which elevate the ball to the same altitude, and thus have trajectories lying between the same horizontal planes, reach the earth or the same lower horizontal plane at different distances at the same time. As a consequence, the descending halves of their trajectories are also covered in the same amount of 
time, i.e., the time needed for horizontal shots to fall from the same altitude (Galilei 1842-56, 6:69-70 [Galilei 1890-1909, 10:229-30]).

These statements, which may be called for short the "law of equal times of fall," strongly imply that Galileo on discovering them was fully acquainted with the principle of the neutral coexistence of different motions of the same body. For the assertion that horizontally shot cannonballs reach the earth at the same time, despite the greatest difference in their horizontal speeds, like a body falling freely from the same height, is simply another way to express the opinion that the motion in the direction of gravity is in no way influenced by the additional motion in the direction of the shot. The certainty with which Galileo formulated these rules appears to suggest that he derived them from principle rather than from experiments, since experiments could not have yielded certain results in this case.

In order to apply this consideration to shots directed diagonally upward, it must also have been known that bodies projected upward need the same amount of time to rise and fall. According to Paolo Sarpi, Galileo already had recognized this before 9 October 1604 (Galilei 1842-56, 8:29 [Galilei 1890-1909, 10:114]).

Thus when he discovered the law of equal times of fall, Galileo knew everything necessary to determine both components of the trajectory in detail, and therefore, along with the principle of the independent coexistence of motions, everything needed to construct the trajectory. He presented the law of spaces of fall, which determines the changes of the vertical components, as a recent discovery in a letter to Sarpi of 16 October 1604 [Galilei 1890-1909, 10:115-16]. ${ }^{1}$ Probably even earlier was the discovery of the law of inertia in the form in which it still is used to construct the trajectory in the Discorsi of 1638 , i.e., in its restriction to motion in the horizontal plane. Direct deduction led from this to the uniformity of motion in the direction of the horizontal shot, and thus everything necessary to determine the horizontal components. To derive this third premise of his construction, Galileo referred in the De motu proiectorum of the Discorsi to the argumentations of a preceding section of the Latin manuscript [ibid., 8:268]: unequivocal remarks substantiate that at least this part of his reasoning in the publication of 1638 originated in an older text from his days in Padua. It may be sufficient here to point out that Castelli, in an April 1607 letter [ibid., 10:169-71], presented as Galileo's theory: "For motion to begin the moving body is required, but for the continuation of motion it is sufficient that it find no resistance" [ibid., 10:170]. ${ }^{2}$

According to this, when he first spoke in 1609 of a book about the theory of

1 This letter was printed in accordance with the original kept in Pisa for the first time in Favaro 1883, 2:226-27 [reprinted in Favaro [1883] 1966, 2:172-73].

2 This remark, first published in Favaro 1883, 2:268 [reprinted in Favaro [1883] 1966, 2:203], was not known to me during my work on the treatise about the discovery of the law of inertia (Wohlwill 1883-84). It apparently contradicts the opinion conveyed there that Galileo restricted the principle of unchanged conservation of motion to the horizontal motions. In truth, even Castelli's remark merely proves that this limitation, which was determined by individual causes in Galileo's work, was not noted by his students, as I attempted to prove for Cavalieri and Torricelli. For further comments by Galileo about inertia in the horizontal direction, see the treatise cited above. 
projectile motion as a component of his work De motu locali, Galileo possessed all prerequisites for the correct construction of the trajectory. To see as many trajectories in parabolic form as he liked, he needed only to make exact drawings rendering the law of equal times of fall on the basis of these discovered facts. For the final discovery, it was necessary, of course, that he recognize the parabola in his drawing. It is not thoroughly inconceivable that one could miss this, even if what lies before one's eyes is the long-sought solution to a riddle. But when Galileo said thirty years later, "I saw then what was before my eyes," it would take strong reasons indeed to convince us of the contrary.

However, several facts are known which justify any doubts at first glance. In the Dialogue Concerning the Two Chief World Systems, published in 1632 [Galilei 1632], among numerous other propositions of the new theory of motion there is no mention of the parabolic shape of the projectile trajectory. Moreover, in the section concerning the construction of the actual path of a body falling to earth and simultaneously affected by the rotation of the earth, essentially the problem of the projectile trajectory, the procedure imparted for constructing the trajectory would indeed result in a parabola if performed correctly. In the Dialogue, however, the result of the combination of the two motions, according to Salviati, is a motion along a semi-circle, not a parabola, and Sagredo rejoices in this unexpected result [Galilei 1890-1909, 7:190-91]. Did Galileo keep his better knowledge secret in this case, or did he not know, when he wrote this part of the Dialogue and even later when he published his book, the true form of the trajectory?

A second, perhaps even greater difficulty is presented by the fact that a few months after publication of the Dialogue, Father Bonaventura Cavalieri, Galileo's pupil, published the correct solution sought in vain in the Dialogue, and made no mention there of the fact that what he imparted was Galileo's discovery. It is true that Cavalieri prefaced the two chapters on the theory of motion added to his book, Lo Specchio ustorio overo Trattato delle settioni coniche, the remark that what is presented in these sections originates "in part" from Galileo and Castelli, his two teachers [Cavalieri 1632, 151-53]. He then explained the three propositions he utilized for the construction of the trajectory in close connection to the arguments of the Galilean Dialogue, thus eliminating any doubt that his derivation was based on Galileo's thought [ibid., 153-72]. But whether Galileo himself came to the same result long before him using the same or similar means cannot be inferred from the chapter on the trajectory in the Specchio ustorio. Rather, the fact that Galileo is not named in the relevant explanations suggests that the author wished to portray them as his own conclusions, as the "part" which did not belong to his two teachers.

A letter Cavalieri wrote to inform Galileo of the contents of his manuscript immediately before publication appears to concur with this interpretation.

I touched briefly on the motion of projected bodies, by showing that this motion, excluding air resistance, must occur in a parabola if we assume your 
principle concerning the motion of ponderable bodies, according to which their acceleration corresponds to the increment of the odd numbers proceeding from the one. However, I declare that what I mention here I learned in great measure ${ }^{3}$ from you, while at the same time I present my own derivation for this principle. (Galilei 1842-56, 9:286 [Galilei 1890-1909,14:378])

Here, too, Cavalieri acknowledged that his proof is based on Galileo's theory of uniformly accelerated motion; but even from this direct pronouncement, the impartial reader would not receive the impression that Cavalieri was conscious of directing his words to the discoverer of the parabolic shape of the trajectory.

That Cavalieri in the end believed to have found Galileo's true opinion in the argumentations of the Dialogue mentioned above becomes preeminently probable through a remark at the close of the penultimate chapter of his Specchio ustorio. There, to the proof that the curvature of a circle of very large diameter would not diverge essentially from that of a parabola and a hyperbola he added:

This realization should satisfy those who believed that the path described by a projected body would be circular. For if the circle in question is of considerable size, and the path of the ponderable body is only a small part of the entire periphery, its divergence from the parabola would be negligible. [Cavalieri 1632, 218]

It is hardly arbitrary to seek in this remark a reference to Galileo's considerations in the Dialogue, since there is no other place in which the circular motion of projected bodies was asserted with similar determination.

II.

The derivation of a circular path in the Dialogue and Cavalieri's mention of a discovery by Galileo, veiled as it may have been, already have been the subject of many critical discussions. It has not been overlooked that facts exist here which contradict per se the general assumption that the parabolic shape of the trajectory was discovered before 1610 . However, not even those who see this as problematic have considered calling into question Galileo's discovery. Such a solution appeared precluded by Galileo's answer to his pupil's preliminary announcement and through Cavalieri's response to this answer. In 1632 Galileo claimed credit for the discovery in no uncertain terms; Cavalieri in his response called Galileo's claim to this discovery one of many well known to contemporaries and one not doubted by himself. The words expressed by both men on this occasion rule out any doubts about the truthfulness of their testimony.

Caverni's opposing view is based on his own peculiar conception of the apparent

3 The "in parte" in the book has become here "in gran parte." 
contradictions mentioned here. To him the remarks outlined in the Dialogue do not appear to be incompatible with all else that is known about Galileo's theory of projectile motion; rather he sees this explanation about the circular path of a body falling on the rotating earth as Galileo's true opinion about the form of the trajectory as well. Caverni believes that Galileo held to this view for forty years with only minimal changes, and he finds this contradicted only by the dominant opinion that Galileo was the discoverer of the parabolic shape and by a similar claim raised in the Latin section of the Discorsi.

Specifically, Caverni believes that the theory to which Galileo professed until the year 1632 is that of Niccolo Tartaglia. According to this, the motion of a projected body consists in part of pure violent motion and, immediately subsequent to this, pure natural motion. The pure violent motion consists of a straight portion and a curved portion; the curve of the latter is circular in shape. As already implied here, in another sentence of his Scientia nuova [Tartaglia 1537] Tartaglia expressly denies that the motion of a projected body in any portion of its path could be mixed, i.e., simultaneously violent and natural. This must have been Galileo's view in essence, not only in 1609 , but even at the time the Dialogue were published. He would have moved beyond this system of Tartaglia's only to the extent that he later acknowledged, under the influence of other researchers, the possibility of both kinds of motion coexisting.

Anyone naive enough to believe that such an interpretation cannot be regarded as proven without supplying literal citations to demonstrate unequivocally that Galileo believed in Tartaglia's teachings over such a long period has got rid of Caverni's argument; for in truth there is no such evidence, and nor does Caverni supply any. However, he does discuss, in an extraordinarily verbose explanation of no fewer than thirteen densely printed, large-sized pages, a number of quotes of the most varied content which bear some resemblance to evidence [Caverni 1891-1900, 4:517-33]. Thanks to Caverni's peculiar way of mixing indistinguishably the words of others with his own commentaries, he manages to create the impression that they confirm his assertion. As they constitute the actual basis of his argumentation, these quotations must be discussed here in turn.

The investigation begins with the treatises written in 1592 at the latest, and with the fragment of a dialog which was printed under the title De motu in Volume I of the Edizione nazionale [Galilei 1890-1909, 1:243-419]. Anyone who seriously studies these oldest notes preserved in Galileo's hand will recognize no more than the precursor of the actual scientific development of thought during the Padua period. Therefore it would be irrelevant to the question under discussion whether any proof could be found in these older manuscripts that at the time of their creation Galileo thought no differently about the trajectory than Tartaglia. But in a truly honest search, one could not discover even here what Caverni claims to have found. The treatises and dialogs of De motu contain not only no mention of a construction according to Tartaglia, but no word at all about the shape of the trajectory, and consequently no indication that Galileo attributes a circular form 
to its middle section. Neither does the Pisa manuscript indicate, as Caverni avers, that Galileo contradicted Cardano and Benedetti and agreed with Tartaglia that a mixture of violent and natural motion is impossible at any point of the trajectory. Caverni has no other proof for this assertion than the remark that "the rotation of a sphere whose center coincides with that of the world is neither a natural nor a violent motion" [Caverni 1891-1900, 4:513].

I have shown elsewhere (Wohlwill 1883-84, 74-5) that this remark very probably related to Galileo's first efforts to understand the perpetual rotation of the earth. He noted that the parts of a homogenous ball made of ponderable matter, concentric with the sphere of the world, neither can approach nor move away from the center of the world through its rotation. He concluded from this that such a motion, in addition to the natural and violent motion, has a peculiar status which appears to be compatible with the permanent conservation of the impetus imparted.

Needless to say, Galileo explained in detail that the above applied to the rotation to no ball, homogeneous or non-homogeneous, located anywhere other than the center of the world; thus it also could not refer to the circular motion of projected bodies. Caverni is audacious enough to create this connection by saying: "thus it is also for the projected bodies" (cosi avviene dei proietti) [Caverni 1891-1900, 4:513]. He would have the reader believe that Galileo, like Tartaglia, held that projected bodies move in a circle so that they neither approach the center of the earth nor move away from it!

That Galileo, at this time by no means denied, in contrast to Cardano and Benedetti, the possibility of "mixed" motion, is evident from definitive explanations given in treatises such as the dialog De motu. His examination of the motion of the vertically projected body concludes that this motion, under the simultaneous influences of gravity and the projective force from the start of the climb through the descent, is mixed, i.e., composed of natural and violent motion (Galilei $1890-1909,1: 322) .{ }^{4}$ For the descent from horizontal shot, however, the last treatise of the Pisa manuscript contains an observation about the mixture, or the coexistence of the motion in the direction of gravity with that in the direction of the shot. This essentially agrees with the explanation published 46 years later, despite very different wording. In the Discorsi it reads:

As soon as the horizontally moved ponderable body leaves the fixed support, it will add the downward inclination caused by its own weight to the previously uniform and indestructible motion. Accordingly a compound motion will result, which I call projectile motion. [Ibid., 8:268]

As a further explanation he adds later that the two motions and their velocities, in

4 "Mixed," i.e., composed of natural and violent motion, in his early work (Galilei 1890-1909, $1: 373$ ) is also called the motion of the body projected diagonally upward; here it is, however, doubtful whether the expression refers to the double motion of a single point. 
mixing with each other, do not change, disturb, or hinder each other. The following explanation in the early work corresponds to this:

Should the projected body move in a direction nearly parallel to the horizon, it can begin immediately to incline and thus diverge from the straight line of the projection; for it is enough for the violently impelling force that it removes the body from the starting point of the motion, and this removal is not hindered by the inclination. ${ }^{5}$

This assertion hardly suggests opposition to the idea of a mixed movement in Tartaglia's sense; on the contrary, it demonstrates a serious effort to clarify the nature and the cause of the mixture recognized.

In order to support his argument, it was far more important for Caverni to gather evidence from the heyday of Galileo's professorship in Padua, especially from the period between 1602 and 1609. Caverni himself attributes the bulk of the Latin sections of the Discorsi to this period because of its main content; nevertheless he believes that he can prove that this is impossible for the main ideas of the theory of projectile motion. In truth, his efforts meet with a lack of evidence in this period, too, which he fills with assumptions and insinuations. A highly unusual role here is played by a sentence about the trajectory published in 1844 [recte 1841] by Libri in his History of the Mathematical Sciences in Italy [Libri 1838-41] from a manuscript of the Paris Bibliothèque Nationale. According to Libri, the manuscript and the sentence originate from Galileo's friend and mentor, the marquis Guidobaldo del Monte. The sentence, remarkable in any case, reads as follows:

If one throws a ball with a catapult or with artillery or by hand or by some other instrument above the horizontal line, it will take the same path in falling as in rising, and the shape is that which, when inverted under the horizon, a rope makes which is not pulled, both being composed of the natural and the forced, and it is a line which in appearance is similar to a parabola and hyperbola. And this can be seen better with a chain than with a rope, since [in the case of] the rope $a b c$, when $a c$ are close to each other, the part $b$ does not approach as it should because the rope remains hard in itself, while a chain or a little chain does not behave in this way. The experiment of this movement can be made by taking a ball colored with ink, and throwing it over a plane of a table which is almost perpendicular to the horizontal.

Although the ball bounces along, yet it makes points as it goes, from which one can clearly see that as it rises so it descends, and it is reasonable this way, since the violence it has acquired in its ascent operates so that in falling it overcomes, in the same way, the natural movement in coming down so.that the violence that overcame [the path] from $b$ to $c$, conserving itself, operates so that from $c$ to $d$ [the path] is equal to $c b$, and the violence which is gradually lessening when descending operates so that from $d$ to $e$ [the path] is equal to

s [Wohlwill freely summarizes from Galileo 1890-1909, 1:339-40.] 
$b a$, since there is no reason from $c$ towards de that shows that the violence is lost at all, which, although it lessens continually towards $e$, yet there remains a sufficient amount of it, which is the cause that the weight never travels in a straight line towards $e$. (Libri $1838-41,4: 397-98$ ) (see fig.1)

The author here, like Cardano before him, tells only to which line the trajectory is "similar in its appearance" (in vista simile) and in this context he mentions both parabola as well as hyperbola. This mere fact proves that with this reasoning he aimed at nothing less than actually constructing the trajectory. On the other hand, his definitive assertion that the two branches of the trajectory are equal to each other and that no part of it is straight is illustrated in too uncertain terms and not proven at all. Only an arbitrary interpretation would find in these few words that which Caverni reads in them: the opinion that any point on either branch of the trajectory at the same horizontal have the same velocity. The word velocity does not occur in del Monte, who speaks only of the concurrence of the shape at the corresponding points. This concurrence could not be explained if velocity did not increase during descent in the same manner as it decreases during ascent. This does not justify Caverni's extrapolation from the above sentences that del Monte assumes that the "violent motion" remains unchanged in both the horizontal and the vertical because his assertion is true only under this precondition. Such fundamentally new insights should hardly be read between the lines of a sentence that fails to distinguish between horizontal and vertical propulsion and states only that "violence" is conserved, albeit gradually decreasing, until the end of the motion.

The extent to which these handwritten notes by del Monte ever could have had importance for the development of the theory of projectile motion can no longer be determined; it is not known whether any expert ever saw it before Libri. It is not

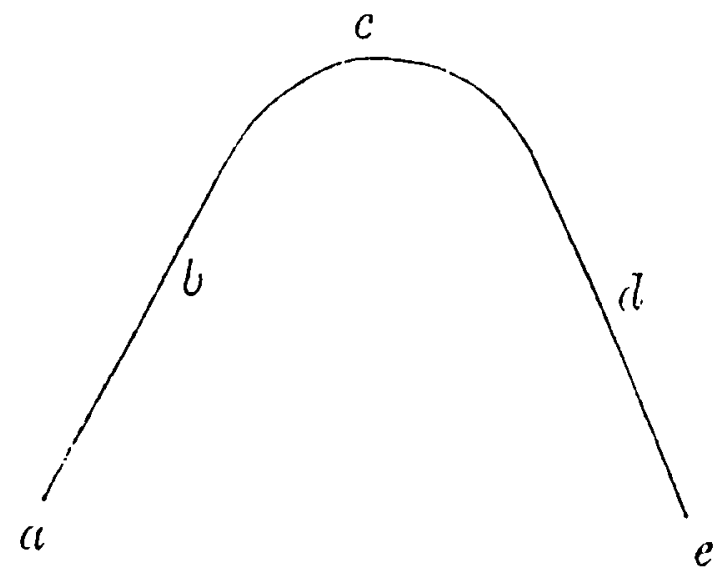

Figure 1.

' Prof. Favaro was good enough to check in the Bibliothèque Nationale that Libri reproduced the original correctly. Translated from the Italian original by Jürgen Renn. 
improbable that its contents were the object of oral discussion or written debate between del Monte and Galileo. Cavalieri relates that around 1622 the engineer Muzio Oddi informed him that Galileo and del Monte had carried out an experiment on the shape of the trajectory [Caverni 1891-1900, 4:516; Galilei 1890-1909, 14:395]. This must have happened before the year 1607, for del Monte died in January of that year. It is conceivable that this experiment was the one described by del Monte, for Galileo cited a similar one in the Discorsi of 1638. In Galileo's depiction the experiment was his own, invented as a means of drawing parabolas, whereas del Monte spoke only of a line which looks similar to a parabola and hyperbola. In this passage Galileo also ascribed the parabolic shape to the freely hanging chain fixed at both ends [Galilei 1890-1909, 8:185-86].

If we try without bias to infer from the combination of these late assertions by Galileo together with the remarks by Oddi and the contents of del Monte's handwritten note an insight about a connection between Galileo's and del Monte's research on the theory of projectile motion, we will obtain a number of possible interpretations, but no historical conclusion. If we allow probability to be considered, it is unlikely that in a collaboration of any kind between two men the decisive impulse comes from the older man. Del Monte's achievements lie in another area; the fragmentary note about the trajectory is all we know of del Monte's studies on issues of the theory of motion. In contrast, upon del Monte's death Galileo could look back at nearly two decades of uninterrupted and most successful research dedicated to these issues. In order to believe that Galileo in 1606 would still find del Monte's observations concerning the theory of projectile motion rational, let alone instructive, we would have to dismiss all our inductions from the known data concerning the path of development of his thought.

In his History Caverni set forth a completely opposing view of the situation, not as the better founded or more probable but rather as the only possible, and based on it his freely invented reconstruction of an unascertainable course of events. For him it is a certainty that the original or a copy of del Monte's manuscript fell into Galileo's hands soon after 1607 , and that Galileo found in it forthwith propositions pertaining to acoustics, the theory of solid bodies and to the theory of motion, which he thought to make his own at an appropriate occasion. Knowing that he might be held accountable for such behavior by those familiar with the contents of the manuscript, Galileo (so Caverni believes) in order to forestall suspicion, spread the tale of the jointly performed experiments.

In keeping with his foible for inventing history, Caverni improves the documents through minor omissions and additions. While Cavalieri heard talk of "an experiment" (qualche esperienza), Caverni has him hearing talk of "experiments with cannons." Because of this alteration it is even easier for Caverni to present the experiments as a fabrication, for others also would have heard of experiments with cannons, and yet "we have no certain document, no report which even suggests such events" (Caverni 1891-1900, 4:516).

Caverni even corrected del Monte's decisive text for his purposes by omitting 
the words et iperbola after parabola, thus increasing considerably the particle of truth in del Monte's words. In Caverni's portrayal it appears that del Monte left his successor little more than to deliver the proof for a truth which was already established. Galileo's constraint in this earlier period then would be all the more prominent, for despite his supposed tendency to adopt anything useful from the legacy of his friend, he rejected its best part. Thirty years passed before he saw the light and included in his own dialogs the instructions for drawing a parabola from del Monte's manuscript.

"Galileo rejects the similarity to the parabola," which del Monte revealed to him; he even "denied it determinedly when his friend showed him the paint marks of the balls on his polished board," so Caverni relates to the reader (ibid., 4: 524, 531). Yet, such a rejection by Galileo cannot be found in his own outlines from previous or later periods, nor in the report of a contemporary; neither with reference to del Monte's words, nor in any other context. It is a product of the historian's fantasy, who, as on many other occasions, finds it superfluous to enlighten his readers. What he presents in the form of an historical account is nothing more than a report about how he believes events proceeded.

In a similarly misleading reconstruction, Caverni imparts his view of how the inspiration Galileo found in the notebook left behind by del Monte came to bear fruit in his theory of projectile motion. He describes in detail how Galileo's argumentation grew out of del Monte's propositions, culminating in the year 1609 when he conceived, or at least surmised, the law of equal times of fall [ibid., 4:517-19]. For in keeping with the tendency Caverni pursues in this fiction, he does not allow the law, as formulated in Galileo's words, to appear as an inevitable deduction, but rather as an indemonstrable presumption. Only in this way could the law of equal times of fall find room in the same mind which, due to a persistent belief in Tartaglia's theory, dismissed the trajectory's similarity to a parabola.

Caverni did not overlook the fact that the most important insights contained in the letter to the Medici prince could be derived much more simply from the principle of the combination of motions. However, he believes that he can prove that Galileo only came to understand the "mixed motion" significantly later. According to him [ibid., 4:521-23], Galileo only in a letter to Ingoli in 1624 [Galilei 1890-1909, 6:509-61], in reasserting the independence of time of fall from the shot range, adds the remark that this can be proven geometrically; a similar remark cannot be found in the letter of February 1609. In Caverni's opinion, this appears consistent with the fact that the theory of indifferent coexistence of dissimilar motions was advanced clearly for the first time in the letter to Ingoli; therefore Caverni believes that the discovery of the new principle [of mixed motion] must be dated shortly before 1624. The letter to Ingoli links the argumentation on this subject to research on the phenomena of motion on the moving earth; thus Caverni assumes that his study of the Copernican system gave Galileo cause to develop his own principle. Trying to disprove physical objections against the motion of the earth led him to conceive that a body in free fall, which simultaneously takes part 
in the motion of the space surrounding it, executes each of these motions as if the others did not exist. He then understood that for this reason [the coexistence of motions] a body falling from a crow's nest comes to rest at the foot of the mast, regardless of whether the ship is in motion or at rest. And only now, Caverni thinks, could Galileo also understand the intrinsic necessity of what in 1609 he had only assumed about equal times of fall.

As probable as it is that his intensive occupation with Copernican theory bore fruit for Galileo's general theory of motion, ${ }^{7}$ the idea that this fundamental idea emerged in the year 1624 must disturb anyone concerned with his scientific biography. This would mean that it had not occurred to him in the preceding thirty years - during which his primary considerations were the system of the earth's motion and the refutation of its opponents.

There is no need to demonstrate the absurdity of a chronology of Galilean discoveries which assumes that the date of first publication is also the date of discovery. Such a chronology would move the discovery of the laws of fall approximately to the age of 65 , had not a letter preserved by chance informed us that the most important of these laws was known to Galileo in $1604 .{ }^{8} \mathrm{~A}$ similar chance allows us to prove that Galileo interpreted the occurrences of motion on the moving earth according to the principle of the indifferent coexistence of the motions at least fourteen years before the letter to Ingoli. In annotations on the treatise by Lodovico delle Colombe contesting the rotation of the earth (ibid., 3:251-90), Galileo answers the author's physical arguments briefly, just as in the later letter to Ingoli and in the Dialogue. Colombe's treatise was doubtlessly written in the year 1610 in response to the Nuncius sidereus; Galileo's glosses cannot have been much later, for they contain in a few hints an outline of the critique he conducted in July 1611 in the letter to Gallanzoni [ibid., 11:141-55]. Unless one assumes, in accordance with Caverni's method, that by chance Colombe's foolish book first gave Galileo occasion to concern himself with Tycho Brahe's counter-evidence and in particular with the discussion of the phenomena of motion on moving ships, it appears more likely that the answers he gives the Peripatetic [delle Colombe] are the fruits of an essentially completed theory. Thus there appears to be no reason to presume that Galileo in 1609 had no inkling of what was at his disposal a year later, and that the law of equal times of fall could not have been discovered or proven at that time in the way we suggested above (see above, page 582). ${ }^{9}$ In any case, neither historical nor psychological reasons can be found for the presumption that Galileo needed del Monte's propositions in order to derive the law.

*****

7 I discussed this view in detail in 1884 (Wohlwill 1883-84).

8 [Wohlwill refers to Galileo's letter to Paolo Sarpi, 16 October 1604 (Galilei 1890-1909, $10: 115-16)$.

${ }^{9}$ [Wohlwill refers to the argumentation exposed in section I of this paper.] 
The discussion about the letter of 1609 [to the Medici prince] is followed in Caverni by information about a previously unpublished fragment which supposedly originated at approximately the same time [Caverni 1891-1900, 4:519]. The manuscript that is attributed to Galileo contains in the form of a series of chapter headings a plan for a work on artillery problems [Galilei 1890-1909, $8: 424]$. The fourth of the fourteen planned chapters was to answer the question of whether a ball will move in a straight line if it is not shot vertically; the fifth was to deal with the path described by the ball shot. Had the chapters been preserved along with these chapter headings, and had the problems and their solutions originated at the same time as of those of the theory of projectile motion about which Galileo reported to the mathematician Luca Valerio, then the instantia exclusiva to resolve the controversy discussed here would have been found within them. Indeed, there can be no doubt that Galileo had not moved beyond the teachings of Tartaglia by this time, if we accept as proven what Caverni reports about the responses to the fourth and fifth questions. "These two problems," he writes, "were solved by Galileo with Tartaglia's arguments"[Caverni 1891-1900, 4:519]. As regards the fourth, the observation put forward by Tartaglia in the second presupposition of the second book of his Scientia nuova [Tartaglia 1537, without pagination] is, indeed, rendered in the words of Simplicio's answer to the question: How long does it take after separation from the hand of the projector for the projected body to begin deviating downward? "I believe," he responded, "that it begins immediately. Since it has nothing supporting it, it is impossible that its own gravity has no effect" [Galilei 1890-1909, 7:221]. Thus Caverni does not report the answer of 1609 here, but rather infers from the Dialogue [of 1632] how Galileo would have answered in 1609 . What is not taken into consideration, however, is that the question Salviati poses to Simplicio hardly coincides with the fourth chapter heading, and that the Simplicio of the Dialogue never represents thoughts and viewpoints new and peculiar to Galileo. There is therefore good reason to doubt that the answer given here is consistent with the entire contents of this fourth chapter. Immediately after the quote Caverni continues,

In full agreement with these (Tartaglia's) principles, Galileo solves the fifth of the submitted questions by saying (dicendo) that the line described by the ball in its motion is in part such that one can consider it a straight line, and in part apparently curved. The curved part will be part of the circumference of a circle, as one reads in Tartaglia's book of the new science.

The above quote is taken verbatim from page 519 of the fourth volume of the Cavernian History, where it appears (of course) with neither quotation mark s nor reference to a source. Nevertheless, the reference to Galileo's words is so unc quivocal that the reader must be a stubborn skeptic indeed to doubt that fragments of these chapters were preserved which give the decisive solution of the controversy. However, the intrinsic improbability of such a solution makes this belief untenable!

Any uncertainty disappeared with the publication in 1898 of the eighth volume 
of the Edizione nazionale of Galileo's works, which includes all remaining and previously unpublished handwritten fragments on the theory of motion. The fragment discussed by Caverni is located on page 424. It contains, like Caverni's transcription, the fourteen chapter headings, but no further indications about the discourse; no second fragment is found that reveals information about the chapter's contents, let alone any that would confirm Caverni's explanation. Thus it is out of the question that a handwritten outline from which the solution of the fifth question could be inferred might exist among the manuscripts preserved at the Biblioteca Nazionale in Florence. Consequently, Caverni, here too, with the words he ascribes to Galileo is merely expressing his own opinion. In view of such argumentation, "no comment" is the best response.

III.

Caverni fails in his attempt to prove that, both during and after the period of his greatest research, Galileo, with respect to the theory of projectile motion, held fast the unrefined ideas of his predecessor and dispensed with any mechanical substantiation of them. The only remark actually preserved from this period is quite simply reconciled with the thesis that the theory of projectile motion of 1609 is in essence that of the "Fourth Day" of the Discorsi. In retrospect, it may be worth noting that even the original drawing included in the letter to the Medici prince contradicts the idea that in February 1609 Galileo still believed in the circular trajectory of projected bodies. This drawing is reproduced in relatively good quality in the Albèri edition (Galilei 1842-56, vol. 6, tav. II, fig. 1 [Galilei 1890-1909, 10:229]). For the purpose of this essay, Professor Favaro was kind enough to supply me with a facsimile he himself made in Florence. The following reproduction allows us to recognize distinctly enough that if Galileo had ever found Tartaglia's figure of the trajectory seductive, this was no longer the case by spring 1609 (see fig. 2).

To what extent proof to the contrary can be gathered from the later remarks in which Galileo has a stone falling to the rotating earth describing a circle remains to be investigated. Caverni drew attention to the fact that these statements, presented

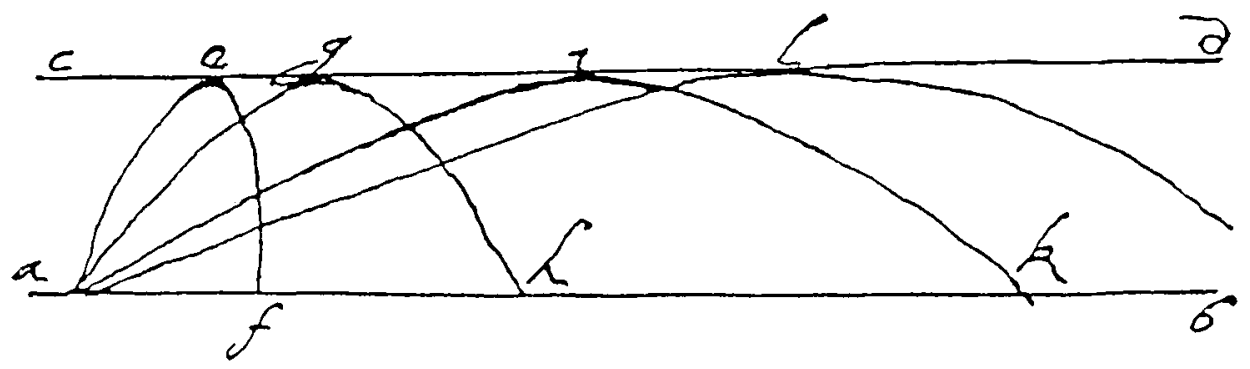

Figure 2. 
in the Dialogue of 1632 , concur with the letter written to Ingoli eight years earlier. "The stone in the crow's nest," is written here,

moves with the same drive as the ship when it is sailing, and this drive does not disappear just because the person holding the stone opens his hand and lets it fall, rather it remains indelibly in the stone so that this, because of the drive, is able to follow the ship. Because of its own gravity, which is not impeded by the drive, the stone also moves downward combining drive and gravity to a single (and perhaps also circular) transversal motion in the direction in which the ship moves. (Galilei 1890-1909, 6:546)

Apparently the expression "et forse anco circolare" indicates at least the possibility of what the Dialogue discuss in more detail. This concurrence, however, should not be interpreted as if we have here two independent statements separated by a number of years, and thus proving persistence in the same opinion over a longer period. According to Galileo's testimony to the Inquisition, he began elaborating the Dialogue ten to twelve years before April 1633, i.e., between 1621 and 1623 . The letter to Ingoli was begun and completed in fall 1624, and thus was written after a number of the subjects in question already had been developed for the Dialogue. Therefore it seems preeminently probable that the discussions contained in both writings about the supposed proof against the daily motion of the earth were created practically simultaneously. This is consistent with the fact that in just these sections of both writings there are similar formulations, some even identical to the letter (Strauss 1891, XLIV-XLV). Hence the words "perhaps also circular" also merely render, in a somewhat condensed form, what is at great length, in part expounded and in part outlined, in the Dialogue. Thus analysis of the decisive passage in the latter text will be sufficient also to explain the meaning of the remark in the letter to Ingoli.

A contradiction contained in the very first sentences of the discussion in the Dialogue (Galilei 1890-1909, 7:189-93) will surely disconcert the attentive reader. Salviati expounds clearly and precisely how to proceed in construction of a trajectory which describes a stone simultaneously falling and participating in the rotation of the earth. He calls special attention to the fact that for the purposes of this construction it is not enough to know that the motion of the falling body is accelerated and that the acceleration is continuous; one has also to know the proportion according to which the acceleration of the falling body takes place. In response to Sagredo's questioning, Salviati then explains that their mutual academic friend (Galileo) discovered this proportion, but that it would require too great a digression to go into details on this occasion. Consequently, the discussion of the relation of acceleration to other factors is put off until a later meeting (ibid., 7:190) and what was just said to be indispensable in order to carry on the construction, and thus solve the problem, is in fact not mentioned. One learns nothing about the law discovered by their academic friend, but in spite of this they take on the construction. Suddenly it appears sufficient to know that the increase 
of velocity is continuous and that the falling body accordingly will pass through all degrees of slowness lying between the resting position and any given velocity. It is demonstrated that as a result of this, the further the falling body progresses along its trajectory, the more the path of the falling stone must diverge from the circumference parallel to the earth's surface. This fact and the additional condition that the line of motion combined from the earth's rotation and the vertical fall must end at the center of the earth appear to determine the nature of this line. That this is not actually the case emerges directly from Salviati's introductory consideration; for the extent of the increasing deviation from that circular line which would be described by the stone in a position of rest is not determined, and cannot be determined with the given preconditions. Therefore, it is put forward as highly probable, but not as demonstrated, that the line in question, beginning at the top of the tower and ending at the center of the earth, is circular. All that is proven is that, if this were the case, three peculiar consequences would have to result: First, the actual motion of the falling body participating in the earth's rotation is, as a simple circular motion, a motion of exactly the same type as that of the body resting on the tower. Second, the falling body moves neither more nor less than if it had continuously remained on the tower, for the curves which it would have traversed in the latter case are exactly the same as those which it traverses in falling. From this the third miracle follows: the true and actual motion of the stone is not accelerated at all, but rather always steady and uniform, as it takes the same amount of time to traverse equal arcs of both peripheries [ibid. 7:192].

After deriving these propositions geometrically, Salviati reminds us that the value of this proof depends on the truth of his unproven supposition. This, apparently, is the meaning of his closing words:

I do not wish to claim at this time that things apply in exactly this way for the motion of falling bodies (here one has the forse circolare of the letter to Ingoli). I do say, however, that if this is not exactly the line described by a falling body, it certainly approximates it extraordinarily closely. [Ibid., $7: 193]$

Sagredo, however, overhears the qualification and concludes with great satisfaction that as a consequence of the rotation of the earth, there are no rectilinear motions left in nature at all. Thus even the function which up until that point had been conceded to rectilinear motion, i.e., returning the separated parts back to the whole to which they belong, is attributed to rotation.

Considering that in this conclusion the most important requirement for the combination of the two kinds of motion, the acceleration due to gravity, is ignored intentionally and that therefore from the start any investigation as to whether the presumed circular shape of the resulting motion complies with the odd number rule is renounced, ${ }^{10}$ the resulting solution can hardly be regarded as serious; in

10 Strauss took the trouble to prove geometrically that this is not the case (Galilei 1891,526 ). 
reality, it constitutes the evasion of a solution. Galileo himself called it a pretense. When Pierre Carcavy informed Galileo in 1637 about the reservations of a friend against the mock construction of the Dialogue, he responded in a letter of 5 June 1637:

that from the mixture of the rectilinear motion of the falling body with the uniform circular diurnal motion would result a semi-circle ending at the center of the earth it was said in jest, as is apparent from the fact that it is called a whim and an eccentric idea (un capriccio e una bizzarria), that is to say jocularis quaedam audacia. Therefore I wish to be granted a dispensation here, all the more since this - might I say - poetic fiction leads to those three unexpected consequences. [Ibid., 17:89]

To this explanation Galileo adds in his letter a further one: As far as the part of the described curve lying over the surface of the earth is concerned, he has no reservations in designating it as a parabolic line, since he asserts that the lines described by projected bodies are parabolae [ibid., 17:90].

According to Caverni, Galileo here dishonestly inserts post-factum as his own ideas what he had since learned from Cavalieri. This interpretation can be rejected with complete conviction. However, the question remains: If Galileo knew this when he concocted his circular line, why did the Dialogue not mention the real truth, which surely was not less interesting than his poetic fiction?

The answer to this question, too, almost certainly can be inferred from Galileo's own words. It is established that his Dialogue was written over a long period of time, and that Galileo changed the plan for the structure of his work several times over the course of this period. The passage discussed here proves that during its composition, Galileo intended to publish his main ideas on the theory of motion in a separate volume. The Dialogue, which was to be published first, was to include just enough about the theory of motion to make it understandable. Therefore the inquisitive Sagredo is referred to the "Treatise of Motion" for details about the law of spaces of fall. If we assume that the treatise, — mentioned here [e.g., ibid., 7:190] as if it were a work already completed -, was identical to or at least, with respect to the main content, congruous with the Latin sections of the Discorsi of 1638 , then already the well-known introduction [ibid., 8:190] to this section makes it clear that, according to the original plans, the Dialogue was to exclude discussions about either the law of fall or about the projectile trajectory for in this introduction the odd number rule and the parabolic shape of the trajectory are strongly emphasized among Galileo's additional new insights as truths "of which nobody previously knew." Had Galileo the intention to publish a second work with such an introduction, he would hardly want to expose in an earlier publication ideas that he later prized as totally new. Therefore he had to do without a clear and correct execution of the construction discussed here.

It seems logical to object against this interpretation that, despite the initial renunciation, the Dialogue contains in later passages not only a derivation of the 
laws of fall, but also detailed considerations about numerous other problems of the theory of motion. A closer examination, however, reveals that these passages were not supplements planned from the beginning, but are rather insertions which clearly contradict the original plan of the work. After thoroughly examining in the "Second Day" of the Dialogue the objections to the daily rotation of the earth and preparing the transition to the yearly motion, the dialogists return again to quite a lengthy discussion of the subjects in hand in relation with an extremely sharp critique of the Disquisitiones mathematicae by Christoph Scheiner, published as early as 1615 [ibid., 7:244-98]. Doubtlessly it was neither this wretched writing nor the wish not to leave it unchallenged which prompted Galileo to reiterate the arguments already established, but rather Scheiner's violent attacks in the Rosa Ursina, which had just appeared in 1631. The apparent purpose of the insertion is to expose his embittered opponent as an ignoramus. Scheiner himself expressed the suspicion that Galileo circumvented the censors to sneak criticism directed against him into the final proofs of the manuscript. Such an insertion long after completion of the edition of the "Second Day" appears to be the only plausible explanation for the multiple repetitions and the contradictions in the final third of this "day."

Apart from the other weaknesses of the Disquisitiones, the calculation of the time of fall of a stone traveling from the moon to the earth offered welcome material to discredit Scheiner. The point here was to contrast his completely misguided calculation with the correct one [ibid., 7:250-51]. "To this end Galileo included a derivation of the laws of free fall [ibid., 7:253-56] and related parts of his theory of motion. He did not deem it necessary, or simply forgot, to reconcile the late derivation with the previous statement that he knew these laws, but did not want to insert them. Consequently, there is no reason for us to consider his subsequent insertion of the laws of fall in our attempt to understand why the previous passage [ibid., 7:191] contains a geometric "joke" instead of the correct derivation of the shape of the trajectory.

Serious people, including Mr. Caverni of course, who find it unbearable to see problems in science taken so lightly, should keep the following in mind. From a superior perspective one may be annoyed with the great man for frolicking through witty games because he does not wish to speak according to his conscience. Those, however, who study history in order to understand people and processes, at least must recognize that joy of wittiness in word and meaning is a significant component of Galileo's cast of mind, and that the remarks about bodies falling in a circular path thus reflected his nature. Similar intellectual games, to be read also as "delightful," but of no value for science, are his hypotheses about the origin of the different speeds of the planets and about the emergence of the acceleration of fall through the interaction of unchanging gravity with the gradually decreasing vis

1 The value of this calculation is immaterial here. On this, see the notes by E. Strauss in Galilei $1891,533-34$. 
impressa. For the latter case, and possibly also for the two previous ones, writings of earlier years prove with certainty that Galileo here puts forward lines of argumentation from times long past that still seem interesting to him although, having acquired a better insight, he no longer considers them correct. Thus in his letter to Carcavy [ibid., 17:88-93], he still seems to consider his false assumption sufficiently justified by the completely surprising consequences it produces. Anyone wishing to pursue the extent to which witty ideas were tempting - and possibly even dangerous ... for Galileo should study thoroughly his letter to the Grand Duchess Christine of Lorraine [ibid., 5:307-48].

\section{IV.}

The preceding elaborations serve only to make plausible that Galileo, as in the Dialogue of 1632, while speculating about the path of the falling bodies, could still be convinced of the parabolic shape of the trajectory. Anyone willing to concede that the episode of the Dialogue might have been created in this manner must thus also concede that no conclusions can be drawn about the contents of the 1609 theory of projectile motion from the arguments exposed there.

Such considerations were alien to the first enthusiastic readers of the Dialogue; historical reflections about the creation of the book, the relationship of the author to his work, his motivations for discussing certain details extensively while holding silence about others, in short, all that is of particular interest to anyone who wants to understand the book historically. Such matters were insignificant to those bombarded by new truths and new conclusions about the half-comprehended or misunderstood; at the time, even the peculiar construction of the "Second Day" was doubtlessly understood and admired as a serious teaching of the master. It should come as no surprise, however, that scholars like Carcavy and his friend, who were dissatisfied with Galileo's argumentation, expressed their reservations without taking any notice of what he, in a sense, "secretly sneaked into" this passage.

We have already mentioned the passage of the Specchio ustorio, - first pointed out by Caverni -, making it highly probable that Cavalieri also interpreted the elaborations of the Dialogue as Galileo's true opinion about the nature of projectile trajectory. In order to judge the extent to which this highly gifted pupil's view allows additional conclusions about Galileo's knowledge in the year 1632, one first must subject to scrutiny how Galileo responded to Cavalieri's announcement about the publication of his Specchio, as well as Cavalieri's reaction to this response.

On 11 September 1632 Galileo answered Cavalieri's previously mentioned communication of 31 August [ibid., 14:377-78] indirectly in a letter to their mutual friend Cesare Marsigli, who like Cavalieri lived in Bologna (Galilei 1842-56, 7:5-6 [Galilei 1890-1909, 14:386-87]). 
I have letters from Friar Bonaventura (Cavalieri) informing me that he had recently printed a treatise about the burning mirror in which, he says, he inserted at a given occasion the proposition and the demonstration that the path of a projected body is a parabolic line. I cannot conceal from you, my venerable sir, that his report pleased me little; for I see how from over forty years of study, a good part of which I shared with the Father in complete confidence, my first fruits are being taken from me and the blossom of the fame which I had promised myself for my endeavors is to be plucked. For in truth the first thing which caused me to speculate on motion was the effort to find this line. Once it is found, the proof for it is not very difficult; I however, who proved it, know how much trouble I had to find this conclusion. Had Friar Bonaventura informed me of his intention before publishing (as perhaps courtesy would have required), I would have pleaded with him to allow me to publish my book first, and then he could have added as many discoveries as he liked. I will wait and see what he produces; but it must be something great indeed to appease my resentment as well as that of all of my friends who have heard of it and now add insult to injury by accusing me of being too trusting. My destiny is to fight for what is mine and yet to lose.

Marsigli and Cavalieri answered this letter on the same day (21 September 1632) (Galilei 1842-56, 9:290-94 [Galilei 1890-1909, 14:394-96]). The latter writes:

The distress you felt, of which the high illustrious Sir Cesare Marsigli informed me, due to my touching upon the parabolic line described by projected bodies in my Specchio ustorio, was certainly not as great as my distress when I heard that you felt offended by my omission, which was due to my excessive reverence more than any other reason. What I said of motion, I said as a pupil of yours and Father Don Benedettos, and as such I declare myself, as you can see from the enclosed sheets, having learned from you, I can say, what little I know. You might surely say that I should have expressed more distinctly that the idea of the parabolic line originated from you, honorable sir. But I wish you to know that my doubt as to whether I was in total agreement with your conclusion kept me from attributing to you with clear words something you might have had to reject as not being your opinion. This fear was the reason for my resorting to the general words on page 152, where I name again Father Don Benedetto, not because I wanted to express that the following originates in part from him, but because he too taught me some of those things, for I saw him performing experiments on them with other pupils from whom I also heard the very same conclusion. In short, it seemed to me that the conclusion is so widely known as you are as its author, that it would be inconceivable that I could claim it as my own property. ${ }^{12}$ As I had the courtesy to write to others, like Sir Muzio Oddi,

12 Professor Favaro was kind enough to collate the original of the letter in Florence at my 
before I published any subjects we had discussed, much more I would have done the same with you (had I thought that you attach importance to it), since $I$ hold you in such high esteem and both honor and love you for your achievements and for the countless favors you did me. If, whilst teaching me, you had intimated to me that I should not make certain ideas known, I would by no means have done so. However, by explaining them to others and declaring them as yours I believed to do what a good student should, while proving to be someone who at least understands, if not imitates your admirable efforts in the unveiling of nature's secrets.

I must add that I truly thought you had written about this somewhere, since I have not been lucky enough to see all of your works. My opinion was supported by the fact that this theory already is known so widely and for so long, since Oddi had told me ten years ago that you performed experiments about it together with Sir Guidobaldo del Monte. I neglected to write to you earlier also because I truly believed that you would not mind, but rather would be satisfied that one of your pupils at such an opportune occasion showed himself to be a follower of your doctrine while acknowledging that he had learned it from you.

Should you deem this a fault, in spite of what I say in my defense, it was certainly not a malicious one. Think about how I can make it up to you, for I am fully prepared to do so. Here in Bologna I circulated only a few copies, and will not distribute any more until the matter is settled to your satisfaction, if this is possible. Therefore I will either postpone further distribution until you have published your book about motion or can publish a predated edition; reprint the two sheets omitting all you view as disadvantageous to you; if you believe my work is in agreement with yours, add in the margin next to line 22 of page 164, the words: "Conclusion of Sir Galileo Galilei," or finally, burn all copies and thus destroy, as far as possible, the root of the displeasure which I have caused my master Galileo, such that he could despair like Caesar: Tu quoque Brute, fili! On the contrary, I always have regarded it as my greatest happiness to have known him, to have been able to honor him and serve him.

Tell me freely which of the options listed would grant you the most satisfaction, for I am most prepared to have it carried out immediately.

These letters presented no obstacle for Caverni's interpretation of the context of events [Caverni 1891-1900, 4:526-30]. For him, the entirety of the documents raised an exclusive claim by Cavalieri to the discovery of the parabolic shape of the

request. This comparison reveals that in addition to several less important deviations, Albèri's transcription left out an entire line here and through this changed the meaning, not insignificantly. The correct text reads: da' quali pure ho sentito l'istessa conclusione parendomi in somma talmente divulgata la conclusione e ch'ella n'era l'autore, che non potesse cadere etc. In Albèri the words printed in bold type are missing [Galilei 1842-56, 9:292]. 
projectile trajectory. He freely fabricates how the reading of the relevant passage of the Dialogue distressed Cavalieri and led him after short contemplation to the correct solution both for the problem put forward in the Dialogue as well as for the mathematically identical problem of the projectile trajectory. Thus in the Specchio ustorio Galileo's tenet is not adopted, but rather disproved. Consequently, Cavalieri's argumentation, according to Caverni's fiction, is focused on just one concern: how Galileo, the strong-willed, passionate tyrant, might react to the fact that he, the pupil, dared to replace his semi-circle with a parabola. Cavalieri is then extremely surprised when, instead of the expected rebuke ${ }^{13}$ for this bold deviation, the news arrives that Galileo himself claims the discovery of the parabolic form.

With the brutal pronouncement: "so many propositions, so many lies!" [ibid., 4:529] Caverni disposes of the melancholy, bitter words with which Galileo claims priority over his pupil. He is not even bothered by Cavalieri's willingness to grant Galileo's claims unconditional recognition by this time, in apparent contradiction to his previous comments. Cavalieri is lying, too, but almost unknowingly. Under the spell of the demoniacal or magical influence which Galileo exercises over him, as Caverni interprets his waiver, "the good man" believes he understands and knows what Galileo wants to make him believe. Will-less, the legitimate owner let himself be persuaded to carry home to the thief what this exacts; will-less, he professes to be convinced that he himself was the burglar [ibid., 4:530].

Even disregarding the fact that here, too, the novelist in Caverni takes over from the historian, passing off a combination of possibilities as history - even considered as a simple attempt at explanation, his portrayal of events is absolutely unfounded. His interpretation of known facts and statements would only be permissible if what he promised to prove to us, but failed to demonstrate in his arguments, had been an established truth.

Even with as little authority as one might grant such interpretations, it is indisputable that some points remain open even after Galileo's letter and Cavalieri's response. The only certainty which emerges from Cavalieri's remarks is the wish for reconciliation with the insulted master. To this end, he exhausts himself in listing the reasons for apparently not recognizing Galileo's right of discovery and not requesting his assent for publication, and in proposals for atonement of every possible transgression, culminating in the complete surrender of his own work. These attempts at justification, however, are not entirely convincing, and Cavalieri's boundless willingness to sacrifice for the sake of reconciliation arouses the suspicion that the given reasons might respectfully hide other ones which have more to do with the truth. Cavalieri asserts having been uncertain as to whether Galileo would recognize as his own his formulation of the proposition of the parabola; but if, as he admits unconditionally, he was certain that Galileo recog-

13 He feared, says Caverni, "to become an object of contempt and of anger for Galileo, as Kepler became for similar reasons" [Caverni 1891-1900, 4:528]. It is known that Galileo never agreed with Kepler's discovery of the elliptical orbits of the planets; but it cannot be proven that he reproached the discoverer for giving up the circular shape, as Caverni suggests here. 
nized the parabolic shape of the trajectory, where could his uncertainty lie? His thesis reads:

Excluding the resistance of the medium, ponderable bodies driven from a projector in any direction other than the perpendicular to the horizon describe from the moment of separation from the projector a curved line which is imperceptibly different from a parabola. (Cavalieri 1632, 164-65)

With the caveat of his final words, Cavalieri referred to the fact that because the vertical component is always perpendicular to the earth's curved surface, over short stretches the trajectory deviates negligibly from the parabola. He could hardly doubt that Galileo would agree with his words insensibilmente differente understood in this sense. Similarly, in the remaining wording of the thesis nothing expressed could have been rejected by anyone who believed the trajectory of projected bodies to be parabolic. If uncertainty about this truly had led Cavalieri to doubt whether he could name Galileo as the discoverer, he easily could have erased this doubt through the correspondence he neglected to initiate! Since he did not wish to refute, on the contrary, he expressly recognized that the essential contents of the thesis belonged to Galileo, it is incomprehensible that he left Galileo's name unmentioned. Cavalieri believed that an adequate substitute for expressly naming Galileo in connection with the parabolic trajectory was the general remark in which he frankly acknowledged owing "in part" to Galileo his insight into the problems of the theory of motion. Yet, a reader of the Specchio ustorio can understand this declaration, at best, in the sense that also the proposition concerning the trajectory may belong to the part of the expounded doctrine for which Cavalieri thanks Galileo, although this is never told explicitly. Furthermore, Cavalieri's subsequent remarks about the general propagation of the theory of the parabola as one originating from Galileo are hardly so definite that they not only would make naming Galileo superfluous but also unthinkable that Cavalieri could have tried to pass himself off as the discoverer. In any case, the theory's presumed wide distribution consisted only of propagation by word of mouth; Cavalieri hardly could doubt, or in any case easily could have found out, that the Specchio ustorio was the first published book in which the parabolic shape of the projectile trajectory was openly taught. If the fact that it was discovered by Galileo appeared so apparent that a preliminary inquiry was unnecessary for publication, this is even less of a reason not to at tribute the discovery to Galileo unequivocally.

Summarizing these objections, one can say that Cavalieri's defense is insufficient to convince of his total sincerity those who, in both the Specchio ustorio and in the August letter, do not find anything more than the explicit attribution to Galileo of the preparatory steps for the discovery of the parabolic shape, but not the discovery itself. In his response to Galileo's letter of 11 September, Cavalieri not only definitively recognized Galileo's priority, but asserted equally decisively that a denial of such a relationship is impossible, neither expressed nor intended in the Specchio ustorio. 
No matter how the apparent contradiction of remarks before and after 11 September 1632 is reconciled, the eccesso di reverenza which Cavalieri himself placed at the head of his defense must have played a role. There is no doubt that for Cavalieri, even if he had discovered the parabolic form himself and not known of Galileo, the words, "I found it!" would have been decisive proof of Galileo's priority. It is even possible that his need to placate the honored master completely was strong enough to induce him to fabricate the story of the theory's general propagation. However, such a fabrication must not necessarily have occurred. Even if Cavalieri in truth had heard talk about Galileo's discovery already in Pisa from Castelli's pupils, and later from Muzio Oddi and many others, the construction in the Dialogue renouncing the parabolic form could have made plausible for him that for some reason the discoverer had exchanged his correct insight for that erroneous tenet presented in the Dialogue as a highly meaningful truth. In such a case, it is understandable that the brilliant mathematician did not forgo publishing in his book, in contrast to the deceiving argumentations of the Dialogue, the simple proof for the parabolic shape based on Galileo's research. No less understandable is that he failed to mention in this particular passage about the projectile trajectory the name of the man who actually discovered the parabolic shape but now dealt with a correlated question in a way as if he would reject his discovery.

This would also explain why Cavalieri speaks of the parabola in the first letter without letting on that it was Galileo's theory he is defending; as a reader of the Dialogue he had reason to doubt whether it still was Galileo's theory.

From this point of view, even the otherwise surprising remarks in the second letter are easy to explain, at least in part. A disciple less full of piety and veneration toward Galileo might have ignored the contradiction of the Dialogue and been able to attribute to him the discovery of the parabolic shape of the trajectory. Cavalieri, however, could not overcome his doubt as to whether somebody who conceived of the path of a falling body on the moving earth as circular could accept the proposition of the Specchio ustorio. This doubt kept him from attributing to Galileo what this had taught in an earlier period.

Even the otherwise almost incomprehensible comment that he believed that Galileo did not trouble himself any more with his theory of the parabola appears justified, if one views the construction of the Dialogue as the point of departure of Cavalieri's doubt. Three years later, another letter from Galileo occasioned Cavalieri to justify once more why he neglected to consult Galileo before publishing the Specchio. This time, he limited himself to explaining that at the time he believed that Galileo attached little importance to his discovery (Campori 1881, 442). ${ }^{14}$

The eccesso di riverenza to which all of Cavalieri's letters to Galileo bear witness explains why neither here nor in his earlier defense he adds that the construction of the Dialogue gave him the most urgent cause to take this view. These letters contain not a single word which could be interpreted as critical; it would be

14 [Bonaventura Cavalieri to Galileo Galilei, 24 June 1635, in Galilei 1890-1909, 16:283-84.] 
impossible to mention the contradiction between the construction of the Dialogue and the correct composition of the trajectory without at least implying criticism.

Instead of this interpretation that limits itself to suppose only the indispensable, consider as more probable that Cavalieri subsequently simulated a knowledge of previous discovery for Galileo's sake and invented fictional facts about this discovery to increase its plausibility. In so doing we would only obtain a condition under which Cavalieri can be seen as an independent discoverer, not at all a sufficient reason to deny Galileo's discovery. For the idea that Galileo could not have discovered and in some way taught something that remained unbeknownst to Cavalieri is in no way substantiated by what we know about the relationship between the two men. If Cavalieri calls himself Galileo's pupil, he certainly meant this in a completely different sense than, for instance, Castelli, Aproino, or Antonini. His relationship to Galileo began nine years after Galileo left Padua and stopped teaching in the usual sense. In 1619 Cardinal Borromeo recommended him to Galileo, calling him a young man of great promise who wanted to dedicate himself to the study of mathematics in Pisa where he then became a pupil of Father Castelli. It can not be established with certainty to what extent Castelli believed himself authorized to initiate Cavalieri into the doctrines which Galileo still reserved for future publication. What Cavalieri's letter of 21 September 1632 relates on this matter suggests more of a coincidental communication than regular teaching. Just as little is known about the extent to which the young mathematician might have enjoyed direct instruction from the man he revered as master during Galileo's occasional presence in Pisa or in Cavalieri's visits to Florence. Galileo speaks unequivocally of such instruction in his letter to Marsigli of 11 September 1632; he does not say so expressly, but he appears certain that Cavalieri, too, has his direct information to thank for the explanation of the trajectory. However, Cavalieri does not confirm this assumption, but rather refutes it with his silence. It was not from Galileo or from Castelli, but from Castelli's pupils and from others that he heard the thesis. This failure to accede to Galileo's allusion is all the more remarkable if one assumes that Cavalieri thoroughly feigns his previous knowledge in order not to contradict Galileo. Not even in this fabrication, where any more or less compliance could make no difference, was he willing to admit that he had Galileo himself to thank for the knowledge of this special theory. In his own opinion, it thus was reconcilable with his Brutus relationship that Galileo did not instruct him personally about a theory to which he attached such great importance.

The Specchio ustorio also fails to offer any evidence opposing this interpretation. Though Cavalieri especially emphasized here that he spoke of the problems of the theory of motion as Galileo's pupil, aside from the parabolic shape of the trajectory, his book contains nothing relating to the theory of motion which could not be and indeed was essentially inferred from the published Dialogue. In short, there is nothing which would suggest that Cavalieri was preferentially initiated in the Galilean theory.

If he was not, or if it cannot be proven that he was, then his supposed ignorance 
can not yield any further conclusions about the contents of the older Galilean theory of projectile motion, let alone be suitable as contradictory evidence when Galileo says, "I found it!"

V.

Caverni's novel has a sequel. In the first volume of his History, he portrayed Galileo as an unscrupulous tyrant, who would stoop even to fratricide in order to consolidate his dominion, if the brother became a rival and the stolen goods could only be enjoyed in security after his elimination [Caverni 1891-1900, 1:127-28, 135-36]. In our case, how did the rapacious tyrant arrange the theft? How did he deal with the brother, who left it up to him to choose between three ways of securing himself for all time against his claims? Caverni tells of this as well; with disgust the reader sees realized the worst expectations raised by the preceding portrayal. Galileo gave his loyal pupil to understand that of the various means which he proposed for atonement, the destruction by fire of the irksome book would please him most; and Cavalieri does not hesitate: he carries out the work of self-abnegation so completely that today it is difficult to find any copy of his book. As early as 1650 this had become so rare that Daviso, a pupil of the great mathematician, recognized as necessary the publication of a new edition [ibid., 4:533].

The factual basis of this story is nothing more than the publication of a second edition of Specchio ustorio in 1650; the remainder is not only unfounded by any document accessible today, but indeed in sharpest contradiction to what one knows about the actual course of events.

Galileo's lively agitation was appeased by Cavalieri's explanations; his letter of 16 October 1632 to Cesare Marsigli documents this. "From the venerable Father Bonaventura," he writes,

I have received a long letter full of apologies. These were truly unnecessary on his part, for I never doubted his best intentions. Rather, I complained about my own misfortune that caused me grief through something done involuntarily and unintentionally. I can not answer him for now since I am extraordinarily busy, so I ask you, Sir, only to tell him that I do not wish the Father to change anything at all in the published book. Rather, I would like to thank him for the honorable reference. (Galilei 1842-56, 7:14 [Galilei $1890-1909,14: 411])$

That Cavalieri received these words as any unbiased reader would today proceeds unequivocally from his response of 7 December, in which he writes: "That you now are satisfied, having seen how I bring up this doctrine, pleases me beyond all measure" (Galilei 1842-56, 9:317 [Galilei 1890-1909, 14:437]).

In the meantime, Cavalieri had sent his book to Florence. In the expectation 
that Galileo would receive it, he asked him for his opinion, particularly in reference to the thoughts exposed in it about the burning mirror of Archimedes, the main reason he had published the book [ibid., 14:438]. Galileo's answer is directed again to Cesare Marsigli. Here one may expect to hear the fratricide speaking at last; but what Galileo writes on 31 December 1632 to his friend in Bologna, in the middle of the upsetting negotiations about the injunctions of the Roman Inquisition, is as full of warm benevolence and of such ungrudging joy at the successes of his younger colleague as these feelings ever have been expressed by a great researcher. "With you, illustrious Sir," Galileo writes Marsigli,

and not with the author of the Specchio ustorio I wish to delight in the wonderful discovery, because I am certain that he who got to the root of it feels such great joy about it that it cannot bear increasing. I must also delight with you when I see the happy progress and the superhuman success of this genial brain, whom I once recommended to you and was favored by you. And if my judgment still has any value for the gentlemen there, I would advise them to grant to this intellect free run through the broad field of the mathematical sciences, along whatever way his genius takes him. This way will be the best of all and incomparably preferable to the calculation of ephemerides or the tabulation of horoscopes. (Galilei 1842-56, 7:14 [Galilei $1890-1909,14: 444])$

After these quotes no more words are necessary to demonstrate that if some kind of secretive machinations obstructed the dissemination of the Specchio ustorio in its first edition, or even caused a considerable part of this printing run to be destroyed, Galileo's opinion and will can not have played a part. Moreover, Caverni still owes a proof for what was to be explained by Galileo's intervention: The 1632 edition of the Specchio ustorio is to all appearances not any rarer than any other books of similar importance from the same era; it is cited almost exclusively in historical works and is quite generally found, for instance, in larger German libraries. The edition of 1650 does not contain the faintest suggestion that unusual conditions made the appearance of a second printing necessary. One may therefore assume that one of the usual reasons for printing second editions of other books some eighteen years after the first prompted Father Urbano Daviso to re-issue the work of his teacher and fellow monk.

Far from offering support for Caverni's unfounded allegations, there is better reason to presume that Galileo himself, through his extremely warm recommendations, contributed not insignificantly to the dissemination of the Specchio ustorio and therefore to the depletion of the first edition. He was not content merely with recommending the book to his friends like Father Fulgenzio Micanzio, and with advising esteemed personalities like Cardinal Capponi to take up personal relations with the author because of his excellent work (Campori 1881, 447, 490); even in public, in his immortal masterpiece [the Discorsi], he mentions Father Bonaventura Cavalieri and his work about the concave mirror, "which he read with 
admiration"(Galilei 1890-1909, 8:86-7). Thus he himself uses expressions reserved only for the greatest of researchers to refer his readers to the book which preceded him by six years in publishing the main proposition of his theory of projectile motion.

In the light of these facts, the story told by Caverni about the Specchio ustorio appears to be preposterous and untrue. As such can also be designated what Caverni reports as further proof of Cavalieri's priority, about the emergence of Galileo's theory of projectile motion in the years 1636 and 1637. A series of letters from the year 1637 shows with certainty that Galileo was occupied with the theory of projected bodies during that period, just before the publication of the Discorsi. He was, in fact, so distracted that his Dutch publisher had to admonish him to send this part of the manuscript after the previous parts already had been printed. "The documents,"says Caverni, referring here to the letters just mentioned, "attest that while the first Latin propositions about accelerated motion go back as far as 1604 , those concerning projectiles were written for the most part in 1636 and 1637" [Caverni 1891-1900, 4:531-32]. Here the strict critic confuses the contents of the "documents" with the object of his argumentation: The latter concerns the Latin sections of the "Fourth Day" of the Discorsi of 1638; the "documents" speak of the whole content of this "Fourth Day" in general, therefore no decisive evidence can be derived from them that these sections written in Latin arose in the years 1636 and 1637. This can also not be confirmed by the established fact that Galileo in 1637 was still occupied with working out the fourth and final part of his work. The "Fourth Day" contains these Latin passages as a smaller section, but most of it was written in the form of an Italian-language dialog explaining and elaborating on the Latin propositions. These letters hardly imply the doubtful thesis that Galileo worked up to publication on the minor, Latin section; it is much more likely that he was occupied with the subsequent, larger part. They speak generally of "proietti" and thus allow us only to recognize that the 73-year old man did what young people are also wont to do in such a case: he worked on the final section of his manuscript up to the last moment before publication.

\section{VI.}

Toward the end of his long indictment, Caverni directs the following challenge to Galileo:

Since you, Mr. Galileo, saw fit to play games with the dignity of your interlocutors and to treat jokingly in your masterpiece a question of such great importance, tell us, in which of the other treatises, letters or notes from your forty years of study of projected bodies you wrote seriously about their parabolic trajectories ... and should you not be in a position to produce a credible document from before September 1632, we can not acquit you of 
the charge of having stolen from Cavalieri the discovery of which you were so desirous, in manner unworthy of a philosopher or of any man of honor. [Caverni 1891-1900, 4:531]

As Caverni issued this bold challenge to the grave of the dead hero, he held in his own hands not a single, but rather a number of such documents which would have refuted his charge decisively and forced him to destroy the greater part of his book, had he been capable of escaping from the dense web of self-deception in which he was entangled.

Through precisely this fourth volume of the Cavernian work which treats the controversy discussed here, it became known to the broader public for the first time that the manuscripts of the Biblioteca Nazionale in Florence include remains of an older treatment of the theory of motion intermingled with drafts for the text of the printed Discorsi [ibid., 4:338-42]. These fragments written in Galileo's hand apparently belong to the Paduan period and will doubtlessly shed new light on the history of his greatest discoveries. Caverni believed it was possible to reconstruct through these manuscripts parts of an earlier draft of a treatise concerning the "new science" which he dates to the years 1602 and 1604-10. According to his explanation, he used arguments of a formal and a material nature to assist in reconstruction. Among the latter he emphasizes the differences in the handwriting in different periods of his life. "It is known to all," he says,

how the writing hand is affected over the years in the same way as the movement of all other members; anyone can experience this in himself, if he compares what he wrote at thirty with what he wrote at fifty. The difference would be without doubt more noticeable were the comparison to be drawn between the writing of early youth and that of old age. However, we restricted our range to the twenty years lying between these manuscripts. These were put aside in 1610 and picked up again systematically in 1630, as it will emerge from the most reliable documents when we will deal with this. The theorems proven between 1602 and 1610 are written in an ink lighter in color and with lighter, rounder shapes. In the year 1630 Galileo's sight, which was so weakened that after a few years it was to fail completely, needed clearer signs; therefore the ink is black, the strokes are thick, and the forms square. (Ibid., 4:341)

It must be left to the Italian scholars, the seasoned experts of the manuscripts preserved in Florence, to express themselves about the reliability of these observations and about their utilization for far-reaching conclusions for the history of science. At this juncture only what is relevant for the Galilean theory of projectile motion is to be emphasized. Here, too, Caverni uses extensively Galileo's unprinted and previously unknown notes. ${ }^{15}$ These refer to most of the questions treated in the

is [Wohlwill refers to the detailed examination of Galilean manuscripts pertaining to the theory of motion in vol. IV, chapters VI-IX, of Caverni's History.] 
Latin texts of the "Fourth Day" of the Discorsi, but deviate somewhat from the sections of the printed work with related content both in wording and in the details of argumentation. Yet all of them unquestionably presume the parabolic shape of the trajectory as a given fact. Therefore it was of decisive importance in championing Cavalieri's discovery to remove all doubt that, according to the "material" arguments discovered by Caverni, not a single one of these fragments can be considered as having been written during the Paduan period or at any time before 1632. Caverni negated this eventuality through silence; from the structure of his book, in which the emergence of the scientific theory of projectile motion is linked to the bereavement of Cavalieri, we infer that he considers all the fragments in which the parabolic shape of the trajectory is presumed as written after the theft. By contrast, every single fragment in which the question of the shape of the trajectory is raised, but not answered, is attributed to the period before 1609 . Even ignoring Caverni's arbitrary interpolation of a non-existent answer, the resulting chronological separation of the fragments also could be interpreted to support the hypothesis argued here. It appears all the more strange that no attempt whatsoever was made to apply the above material criteria to justify more closely the decisive distinction. There is no pronouncement that the written characters from the two periods exhibit the differences portrayed earlier and thus reveal the different ages of the author. Strictly speaking, the only reason to believe in such dissimilarities is the faith that no reasonable historian would evaluate manuscripts of related content arbitrarily, or merely to suit his purposes, by attributing one to the best years of manhood and the other to the beginning of old age.

Publication of the fragments of the theory of motion in the eighth volume of the Edizione nazionale of Galileo's works and the corresponding explanations of the editor [Galilei 1890-1909, 8:33-8, 363-448] have informed us definitively that Caverni used the decisive testimony of the manuscripts against Galileo in the most arbitrary way as evidence supporting his theft hypothesis. Through the publication of the fragments and the explanations by Antonio Favaro the following have been established:

1. The handwriting on those fragments referring to the theory of projectile motion which were found scattered among the sheets of the second part of the fifth section of the Galilean manuscripts indicates that they originate primarily from his youth, but in part from a later period.

2. On several sheets, some of the notes exhibit the youthful handwriting, while other parts in the main text and/or in marginal comments can be recognized through the handwriting as being complements, corrections, or other supplements of a later period.

3. According to their contents, all of the fragments relating to the theory of projectile motion, whether the handwriting attributes them to early or later periods, presuppose in an absolutely unequivocal manner the parabolic shape of the trajectory as an established fact. An exception is the above-mentioned list of questions or chapter headings on the theory of projectile motion, in which the 
question about the shape of the trajectory is formulated, but no further information is given about the contents of the answer.

The publication illustrates the parallel occurrence of the different handwriting in a very interesting way through the supplement of three facsimiles [ibid., 8:428-33]. These also demonstrate how Galileo continued work on the same problems over three decades, and bring to mind how in later years Galileo himself criticized the creation of his youth, how he changed formulations, rewrote and corrected proofs, or treated in detail a proposition only jotted down in a previous period. The word "scritta" scrawled in the trembling hand of an old man, - it seems to us - , points to an even later period, informing us that the text was incorporated into the treatise on projectile motion of the Discorsi.

To the extent possible for a facsimile, the three published in the eighth volume of the Edizione nazionale also clarify the question discussed here. The opening sentence of each of the three, written with a relatively young hand, already speak of the parabolic form. What is obvious even to the layman here is elevated to certainty through the explanation, entered above under "3.", given by the editor of the Edizione nazionale, the profoundest expert of Galileo's handwriting [ibid., $8: 34$, note 1]. In the following, it seems to me opportune to complement this general declaration, which is anyway sufficient in itself, through more exact information about the contents of such fragments which with certainty are to be ascribed to the period of youthful research. Professor Favaro again kindly gave me each of the clarifications I requested.

Among the fragments becoming known only now, my attention was captured primarily by a fragment written in Italian (Galilei 1890-1909, 8:373-74), beginning with the words:

I assume (and perhaps will be able to prove) that the falling ponderable body by nature continuously increases its velocity in proportion to the increases of its distance from the starting point of the motion. ... The principle,

the author continues,

appears to me very natural and in accordance with all experience we see in instruments and machines which operate by percussion: the percutient causes a greater effect the greater the height is from which it falls. Under presumption of this principle I will prove the rest.

Subsequently, as a necessary consequence of the presupposed principle it is deduced in a very peculiar way that the distances traveled by the falling body in equal times relate to each other like the odd numbers $a b$ unitate. To this Galilei adds, "this is in accordance with what $I$ have always said and observed in experiments; and thus all truths are in agreement with one another." Taking the preceding for granted, it is also demonstrated that "the velocity in violent motion decreases in the same ratio as it increases in natural motion along the same straight line."

As is apparent, the fragment essentially agrees with the letter Gaileo wrote to 
Paolo Sarpi on 16 October 1604, reporting about this same (later discarded) fundamental idea and its application (Favaro 1883, 2: 226-27 [Galilei 1890-1909, 10:115-16]). This letter appears as an abbreviated rendering of what most probably was written down for the first time in the fragment. A deviation of the wording of the fragment from that of the letter is worthy of being pointed out. In the former the discovery of the law of fall and the discovery of the explanation based on the proportionality of velocities and distances traveled appear separated chronologically in a way which could not be inferred from the letter to Sarpi. The wording of the latter appeared quite reconcilable with the assumption that the discovery of the law of fall, too, occurred in the year 1604. In contrast, the statement in the fragment, in which Galileo designates the odd number rule as something "che ho sempre detto e con esperienze osservato," forces us to consider the possibility that this truth had been recognized much earlier.

The fragment itself, being doubtless an autograph, can be regarded confidently as having been written shortly before the letter to Sarpi; therefore, it belongs in any case to the second half of 1604. If necessary, this established fact can be taken as an indication for the age of the remaining fragments.

The assumption that the fragment discussed here was written in the writing of Galileo's youth is correct with "absolute certainty" according to Favaro. But with equal certainty, the scholar, whose judgment we must view as authoritative in this relation, recognizes the following fragments belonging to the theory of projectile motion as also written by the youthful hand:

1. Pag. $424^{16}$ (Mss. Gal. P. V. T. II. car. 193 r.): This is the compilation, written in Italian, of artillery problems mentioned many times in the preceding and including the two questions: "se la palla vadia per linea retta, non sendo tirata a perpendicolo" [whether the ball shot not perpendicularly moves in a straight line] and "che linea descriva la palla nel suo moto" [what kind of line the ball describes during its motion].

2. Pag. 427 (Mss. Gal. P. V. T. II. car. 91 t.): Fragment beginning with the words "Determinetur ergo impetus" [The impetus therefore is determined]. In this fragment, consisting of only seven lines and a drawing, the problem is formulated how to determine the impetus at individual points of the parabola from the always constant horizontal impetus and the impetus acquired through vertical fall. Here the horizontal velocity is viewed in the manner known from the Discorsi as acquired through free fall from a corresponding height.

3. Pag. 428 (Mss. Gal. P. V. T. II. car. 110 t.): Numerical example for the calculation of the impetus at different positions of the parabola.

4. Pag. 428 (Mss. Gal. P. V. T. II. car. 87 t.): "Datae parabolae elevationem invenire, ex qua decidens mobile parabolam datam describat." [To find the elevation of a given parabola from which the falling mobile describes the given

16 [This and the following page-numbers refer to vol. 8 of Galilei 1890-1909. They are followed by the call-numbers of the original manuscripts in the Biblioteca Nazionale of Florence.] 
parabola.] The solution and the corresponding demonstration coincide completely with the corresponding solution and demonstration imparted in the printed Discorsi under Propositio V (Galilei 1890-1909, 8:293) with the heading: "In axe extenso datae parabolae punctum sublime reperire, ex quo cadens parabolam ipsam describit." [In the axis of a given parabola extended upward, to find the high point from which a falling body describes this same parabola.] Accordingly, the label "scritta" [transcribed] appears at the foot of the fragment. A comparison of the two headings indicates the extent to which the later version with unchanged content strives for heightened distinctness of expression. A deviation in wording only has also to be pointed out: Galileo in the Discorsi labels as "sublimitas" what is called "elevatio" in the fragment. The word "sublimitas" appears not to occur in what are certainly the oldest fragments. The solution of the problem is immediately followed on page 429 by the deduction that one-half the base is a mean proportional between the altitude of the parabola and the elevation above the parabola. This deduction coincides with the Corollarium to Propositio V of the Discorsi [ibid., 8:294] except that again the word "sublimitas" substitutes in the Discorsi the "elevatio supra parabolam" of the fragment.

5. Pag. 429-30 (Mss. Gal. P. V. T. II. car. 9a r.): The fragment begins by investigating the correlation between horizontal impetus and range of various semiparabolas, as well as the correlation between the variation of the impetus at the foot and the variation of the horizontal impetus of semiparabolas of equal height. Through inversion, the preceding consideration is then applied to parabolas produced by upwards shots in the direction of the tangent of corresponding semiparabolas; for these parabolas too, the correlation is derived between range and different given start impetuses, at first for individual cases of parabolas with equal height. Through calculation of individual examples it is then illustrated, more than proven, that with a shot at an angle of $45^{\circ}$ a greater distance can be reached than with shots of equal force at an higher or lower angle over the horizon. As in the Discorsi, this fragment presumes, but does not prove, that a body projected diagonally upward in the direction of the tangent to the semiparabola produced by a horizontal projection must describe the same parabola [as the body horizontally projected].

6. Pag. 431 (Mss. Gal. P. V. T. II. car. 111 r.): Demonstration that for semiparabolas of equal amplitude, the impetus acquired through projection is smaller when the amplitude is twice as great as the altitude than when it is more than twice as great. The demonstration essentially coincides with the argumentation given for Propositio VII of the "Fourth Day" of the Discorsi [ibid., 8:294-95].

7. Pag. 433 (Mss. Gal. P. V. T. II. car. 111 t.): Beginning of the demonstration for the thesis exposed in Propositio VIII of the "Fourth Day" of the Discorsi [ibid., 8:297] that the amplitudes of two parabolas are equal when the impetus of the projected bodies is the same and the shots occur at angles which deviate equally above and below half a right angle.

The result of this overview can be summarized briefly. From a period of 
Galilean research which surely predated the composition of the Dialogue Concerning the Two Chief World Systems, a number of fragments in Galileo's hand relating to the theory of projectile motion are preserved. In them the recognition of the parabolic shape of the trajectory is presupposed and, moreover, the most important principles deriving from this insight are treated in a similar manner as in the Latin sections of the Discorsi, partly in literal correspondence with these.

Despite this restriction, the result of the examination of the manuscripts suffices to prove that the discovery of the parabolic shape of the projectile trajectory belongs to Galileo and not to Cavalieri, while doubt is at first possible as to whether the differences in the Galilean handwriting can allow an absolutely certain distinction between what was written before and after 1610. However, according to all of the available information in Galileo's correspondence, he concluded his research on the theory of projectile motion in the year 1609 before the invention of the telescope, and returned to the same area of research two decades later at the earliest. Taking this into consideration, the observation that the fragments in question were written by the young Galileo also furnishes unequivocal evidence that they belong to the Paduan period, and thus constitute fragments of that theory of projectile motion on which Galileo reported to Luca Valerio and Minister Vinta. Thus the Latin sections of the "Fourth Day" of the Discorsi, which merely expound that which is essentially in the fragments already, are in truth what they claim to be: they are parts of the manuscript concerning a new theory of motion that had been temporarily finished in Padua. Galileo's theory of projectile motion, as it is presented in the Discorsi, is thus a product of the glorious period of his best years to which the majority of his greatest discoveries belong, and not a discovery made in his old age.

Consequently, despite Caverni's bold accusations, any justification for doubting the credibility of the letter of 11 September 1632 is removed. Every part of the letter is true: Galileo's explanation that the search for the shape of the projectile trajectory was the starting point for his research on motion must continue to serve as before and in the future, as an established datum for the historical interpretation of the development of the new theory of motion.

It is certain that the letter of February 1609 can be regarded as written after the discovery of the parabolic shape, and the law of equal times of fall first formulated there as derived from the recognition of the true nature of the projectile trajectory. When Galileo here counts the comparison of times of fall for balls projected with unequal power in the horizontal direction as one of those remaining problems to be studied (questioni che mi restano intorno al moto dei proietti), this is in complete accordance with the idea that the main propositions of the theory of projectile motion already had been asserted by this time. The law of equal times of fall was merely a further deduction. This seems to be the reason why Galileo did not include in the Latin sections of the Discorsi concerning the theory of projectile motion a conclusion which he often mentioned in other works with particular predilection. 
The objections which have been derived from the Dialogue and from the Specchio ustorio against Galileo's right of discovery are simply reduced to sham proofs when confronted with the evidence given by the manuscripts. This also applies to the many other "proofs" which were constructed and could further be constructed through the interpretation of other passages.

Despite the ultimately decisive importance of the examination of the handwritings, it was nevertheless appropriate that the preceding pages dealt principally with the refutation of apparent counter-evidence, that is, strictly speaking, with the demonstration that what must be considered false on the basis of stronger evidence is at least improbable. The point was not only to answer this one question for which the handwriting evidence would have been sufficient, but rather to interpret the historical context in such a way that even the semblance of a contradiction between the result of the examination of the handwritings and the other established facts vanished. Clear historical insight was only attained with the elimination of this contradiction. There was also a second motive for the exhaustive examination of all adduced causes of suspicion. It was hardly superfluous to show that Caverni's attack would remain untenable even if a happy coincidence had not preserved documents which suffice in and of themselves to refute the charge of theft. The Italian scholar raised other serious insinuations against Galileo's great name and in many cases gave to his insinuations an appearance of reality in the same irresponsible manner as he did in the case discussed above, by combining interpretation and fabrication. In these other cases, though, there are no incontrovertible witnesses to summon to the bar, as we did here, to testify to the hollowness of the insinuations. It was, therefore, important for the examination of these other cases to show in the most complete manner, in a case in which the historical truth is above question, the method according to which all others are constructed. 